\section{National Black HIV/AIDS Awareness Day - February 7, 2020}

National Black HIV/AIDS Awareness Day (NBHAAD) is observed each year on February 7 to highlight the continuing disproportionate impact of human immunodeficiency virus (HIV) infection and acquired immunodeficiency syndrome (AIDS) on the U.S. black or African American (black) population. During 2018, blacks represented $13 \%$ of the U.S. population but accounted for $43 \%$ of all newly diagnosed HIV infections (1).

In February 2019, a new national initiative, Ending the HIV Epidemic: A Plan for America (EHE), was proposed. The plan calls for intensified efforts to diagnose, treat, prevent, and respond to HIV infections in the United States, with an overall goal of reducing new HIV infections by $\geq 90 \%$ by 2030 (2).

A study reported in this MMWR issue presents data on CDC-funded HIV testing and outcomes among blacks who were tested in jurisdictions that are the initial focus of EHE. In these jurisdictions during 2017, blacks accounted for $43.2 \%$ of CDC-funded tests and $49.1 \%$ of newly diagnosed HIV infections (3). CDC supports a range of efforts for reducing the risk for acquiring or transmitting HIV infection among blacks. Additional information is available at https://www.cdc.gov/hiv/group/racialethnic/ africanamericans. Information about NBHAAD is available at https://www.cdc.gov/hiv/library/awareness/nbhaad.html.

\section{References}

1. CDC. Diagnosis of HIV infection in the United States and dependent areas, 2018. HIV surveillance report, vol. 30. Atlanta, GA: US Department of Health and Human Services, CDC; 2019. https://www.cdc.gov/hiv/pdf/ library/reports/surveillance/cdc-hiv-surveillance-report-2018-vol-30.pdf

2. Harris NS, Johnson AS, Huang YA, et al. Vital signs: status of human immunodeficiency virus testing, viral suppression, and HIV preexposure prophylaxis_-United States, 2013-2018. MMWR Morb Mortal Wkly Rep 2019;68:1117-23. https://doi.org/10.15585/mmwr.mm6848e1

3. Essuon AD, Zhao H, Wang G, Collins N, Karch D, Rao S. HIV testing outcomes among blacks or African Americans- 50 local U.S. jurisdictions accounting for the majority of new HIV diagnoses and seven states with disproportionate occurrences of HIV in rural areas, 2017. MMWR Morb Mortal Wkly Rep 2020;69:97-102.

\section{HIV Testing Outcomes Among Blacks or African Americans - 50 Local U.S. Jurisdictions Accounting for the Majority of New HIV Diagnoses and Seven States with Disproportionate Occurrences of HIV in Rural Areas, 2017}

Aba D. Essuon, $\mathrm{PhD}^{1}$; Hui Zhao, $\mathrm{MS}^{2}$; Guoshen Wang, $\mathrm{MS}^{1}$; Nicoline Collins, $\mathrm{MPH}^{1}$; Debra Karch, $\mathrm{PhD}^{1}$; Shubha Rao, $\mathrm{MPH}^{1}$

Identifying persons with human immunodeficiency virus (HIV) infection who are unaware of their status and linking them to care are critical steps in achieving viral suppression and reducing the risk for transmitting HIV (1). In 2017, $43 \%$ of new diagnoses of HIV infection were among persons who self-identify as blacks or African Americans (blacks) (2), who represent $13 \%$ of the U.S. population (3). Fewer blacks, compared with whites, were linked to HIV medical care within 90 days of diagnosis, retained in care, or virally suppressed (4). Ending the HIV Epidemic (EHE) is an initiative intended to reduce new HIV infections by $90 \%$ from 2020 to 2030 (5). EHE's Phase 1 is focused on 50 jurisdictions* that accounted

*https://www.hiv.gov/federal-response/ending-the-hiv-epidemic/overview.

\section{INSIDE}

103 Syndromic Surveillance of Suicidal Ideation and Self-Directed Violence - United States, January 2017-December 2018

109 Anhydrous Ammonia Chemical Release - Lake County, Illinois, April 2019

114 Notes from the Field: Four Cases of Lyme Disease at an Outdoor Wilderness Camp — North Carolina, 2017 and 2019

118 QuickStats

Continuing Education examination available at https://www.cdc.gov/mmwr/mmwr_continuingEducation.html

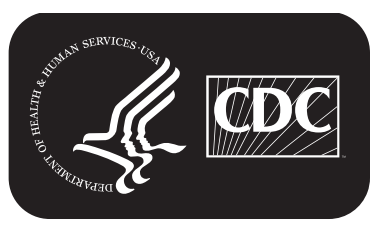

U.S. Department of Health and Human Services Centers for Disease Control and Prevention 